\title{
Finding space to grow urban hedges as a natural air filter along pedestrian paths: a GIS-based investigation of a UK urban centre
}

\author{
${\text { Muhammad } \operatorname{Irfan}^{1} \mathbb{1} \cdot \text { Hishiv Shah }}^{1} \cdot$ Aleksandra Koj $^{1} \cdot$ Hywel Thomas $^{1}$
}

Received: 19 June 2018 / Accepted: 3 September 2018 / Published online: 15 September 2018

(c) The Author(s) 2018

\begin{abstract}
Road vehicles are a significant source of air pollution in cities, with impacts on human health. Previous work has shown that hedges located between the road carriageway and pavement can help to mitigate the impact of vehicle emissions for pedestrians and residents. For continuous improvement of air quality around the city centre area, roadside hedges can be of value. This study has used UK government statistics to map the traffic emissions along major roads in an urban centre. Using appropriate geoprocessing techniques, suitable locations for planting roadside hedges have been identified along these roads. It is envisaged that planting suitable urban hedges at these locations can help further improve air quality.
\end{abstract}

Keywords Roadside hedges · Air quality · Vehicle emissions · Geographical information systems · Urban geography

\section{Introduction}

Road vehicles emit harmful pollutants in the form of particulate matter, nitrous oxides and carbon monoxide (Abhijith et al. 2017), all of which have adverse impacts on human health. Poor air quality is a cause of illness and premature death worldwide. Only in UK, air quality related health services costs around $£ 20$ billion per year (Welsh Air Quality Forum 2016).

Previous studies have shown that vegetation in urban areas can influence the dispersion of pollutants, and also help to remove urban pollutants from the atmosphere (Escobedo and Nowak 2009; Fantozzi et al. 2015; Janhäll 2015; Nowak 2006; Yin et al. 2011). Recently study by Abhijith

This paper has been selected from the 1st Euro-Mediterranean Conference for Environmental Integration, Tunisia 2017.

Muhammad Irfan

MuhammadI2@cardiff.ac.uk

Hishiv Shah

ShahH14@ cardiff.ac.uk

Aleksandra Koj

KojA@cardiff.ac.uk

Hywel Thomas

ThomasHR@ cardiff.ac.uk

1 Geoenvironmental Research Centre, Cardiff University, Cardiff, UK et al. (2017) has shown that among, different types of vegetation, urban hedges are found to be extremely important since they divert airborne pollutants from reaching the pavement by generating local air vortices. Hedges with lower permeability and greater height showed more pollutant reduction. To achieve maximum pollutant reduction at breathing height, studies suggest an optimum hedge height of $2 \mathrm{~m}$, though this will vary depending on the street layout (Gromke et al. 2016; Li et al. 2016). A review of studies by Abhijith et al. (2017) found that hedges reduced pollutant exposure on pavements by between 24 and $61 \%$.

Literature on urban green spaces lacks any significant covering of urban hedges. Mostly the literature covers green belts, parks, forests, green roofs, streams, and community gardens (Wolch et al. 2014). Although a lot of research has been carried out on hedges in Britain, but emphasis has mostly remained on the rural hedges only (Gosling et al. 2016). This shows a significant gap in literature on the use or promotion of urban hedges as a mean to control traffic pollution and improve air quality.

To fill this gap, this study aims to identify and map suitable locations for planting roadside hedges in an urban centre in UK, while taking into account multiple constraints, e.g., pavement widths and access to bus stops, etc. The study also aims to estimate and map total road vehicle emissions along segments of major roads in the same urban centre. By combining these two phenomenon on map, it is envisaged the study can serve as a good guideline for further similar 
studies that can assist the policy makers in addressing the issue of urban pollution through planting urban hedges. For the purposes of this study, hedges are defined as bushes or shrubs growing at ground level. Hedges are usually lower in height than trees, but have a greater leaf density. Hedges are often pruned to a cuboidal shape, particularly when located in built-up areas (Abhijith et al. 2017). Figure 1 shows the study area used for this research, i.e., the city centre area of Cardiff. The study area has been selected because it is the centre of a medium-sized city in the United Kingdom.

Cardiff Centre shows a clear decreasing trend in annual mean nitrogen dioxide concentration from 1992 to around 2000, after which the downward trend appears to level off (Welsh Air Quality Forum 2017). Therefore, continuous focus on further improvement is a key for a better quality of the growing city in future. It is envisaged that urban hedges can play a key role in this regard. Figure 2 shows the $\mathrm{NO}_{2}$ trend of Cardiff City Centre with respect to the three other long running air quality measuring sites in Wales, i.e., Cwmbran, Newport and Port Talbot (Welsh Air Quality Forum 2017).

\section{Data}

This study makes use of UK government statistics on road traffic, road vehicle licensing, and road transport emissions, as well as GIS datasets from Ordnance survey and GetMapping.

\begin{tabular}{|c|c|}
\hline Dataset & Format \\
\hline $\begin{array}{l}\text { Department of transport average } \\
\text { annual daily flow }\end{array}$ & Comma separated values (CSV) \\
\hline $\begin{array}{l}\text { Department of transport vehicle } \\
\text { licensing statistics }\end{array}$ & Open document spreadsheet (ods) \\
\hline $\begin{array}{l}\text { National atmospheric emissions } \\
\text { inventory }\end{array}$ & Excel workbook (xlsx) \\
\hline $\begin{array}{l}\text { Ordnance survey MasterMap } \\
\text { topography layer }\end{array}$ & $\begin{array}{l}\text { Geography markup language } \\
\text { (GML) }\end{array}$ \\
\hline Ordnance survey open roads & $\begin{array}{l}\text { Geography markup language } \\
\text { (GML) }\end{array}$ \\
\hline Getmapping aerial imagery & JPEG \\
\hline
\end{tabular}

\section{Average annual daily flow}

The average annual daily flow (AADF) dataset, produced by the Department for transport (DfT), gives the number of vehicles that drive on a particular stretch of road, on an average day of a particular year. Figures are produced for major roads on a yearly basis, with each stretch of road defined from junction to junction (Department for Transport 2018a). This study made use of AADF figures for the year 2016.

\section{Vehicle licensing statistics}

The department for transport produces statistics on licensed road vehicles, derived from data held by the Driver and Vehicle Licensing Agency (DVLA). This study made use of statistics on the percentages of licensed cars and light goods vehicles (LGVs) propelled by petrol or diesel fuel, for the year 2016 (Department for Transport 2018b).

\section{National atmospheric emissions inventory}

The National atmospheric emissions inventory (NAEI) provides emissions factors for a range of pollutants relevant to road transport. This study made use of the NAEI's fleet-weighted hot exhaust emission factors for nitrogen oxides $\left(\mathrm{NO}_{\mathrm{x}}\right)$, coarse particles $\left(\mathrm{PM}_{10}\right)$, fine particles $\left(\mathrm{PM}_{2.5}\right)$, and carbon monoxide (CO). Hot exhaust emissions are the tailpipe emissions in $\mathrm{g} / \mathrm{km}$ from a vehicle with its engine warmed up to its normal operating temperature. The NAEI provides hot exhaust emissions factors for a combination of different vehicle types, fuel types and road types. These data are weighted to reflect the composition of the UK fleet and journeys made in the year 2014 (National Atmospheric Emissions Inventory 2018).

\section{OS MasterMap topography layer}

OS MasterMap topography layer is the most detailed topographic map produced by Great Britain's national mapping agency, the Ordnance Survey (OS) (Ordnance Survey 2018a). Importantly for this study, OS MasterMap topography layer maps the locations of roadside features, such as verges or pavements. This study made use of OS MasterMap topography layer data for a $9 \mathrm{~km}^{2}$ area.

\section{OS open roads}

OS open roads is a digital representation of Great Britain's road network, produced by the Ordnance Survey. It forms a topologically connected link and node network, where links represent the approximate central alignment of the road carriage way, and nodes represent road junctions (Ordnance Survey 2018b). This study made use of OS open roads data for a $9 \mathrm{~km}^{2}$ area. 


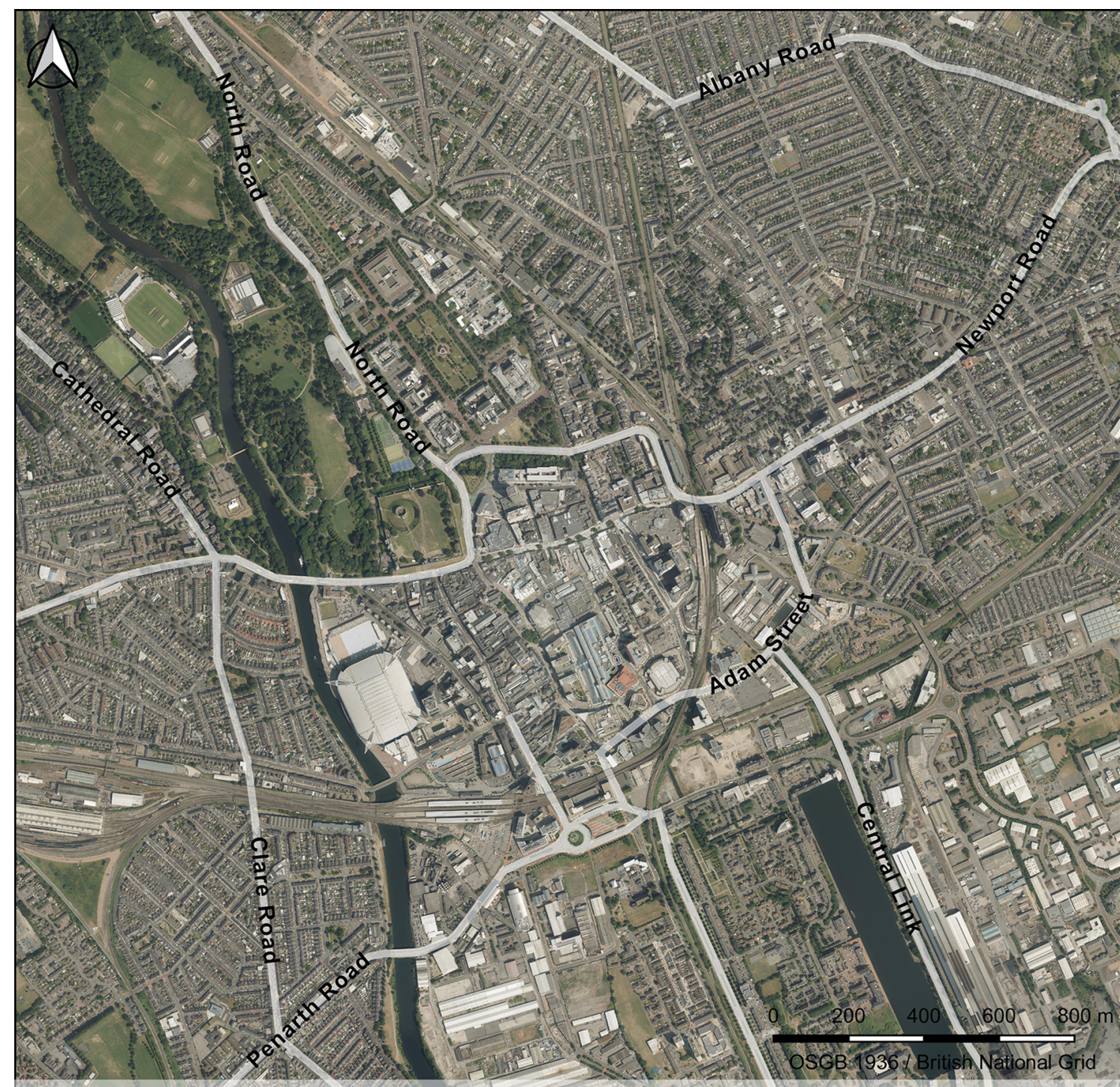

(c) Crown copyright and database rights 2018. Ordnance Survey (Digimap Licence). Aerial imagery () Getmapping Plc.
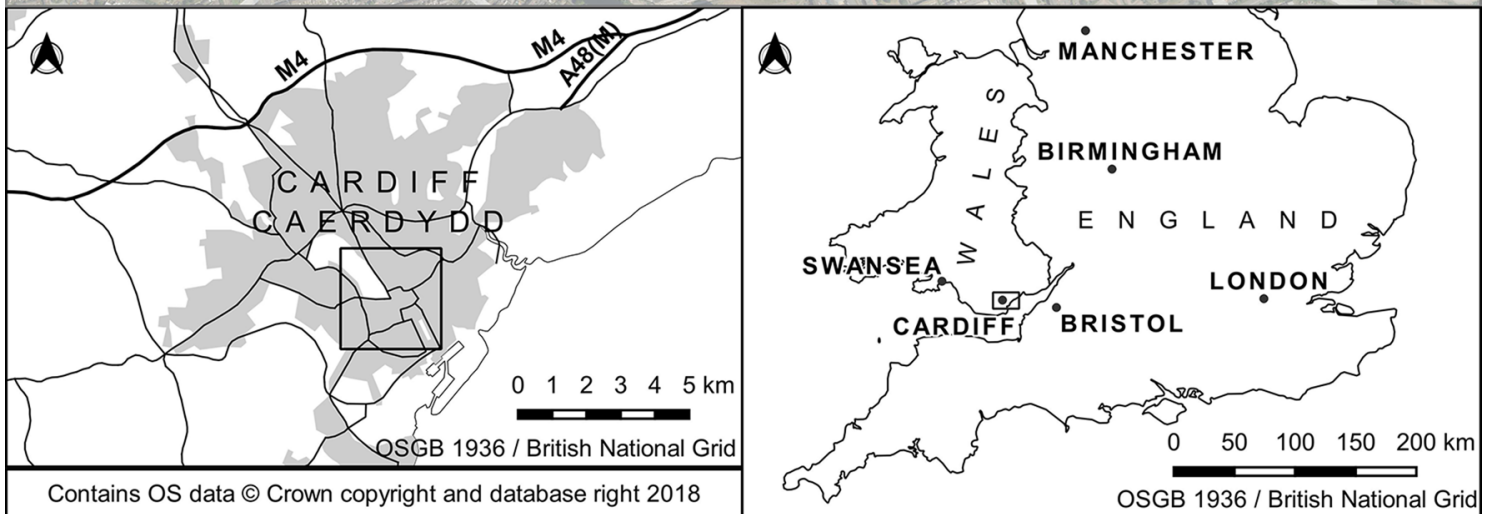

Fig. 1 Location of the study area 


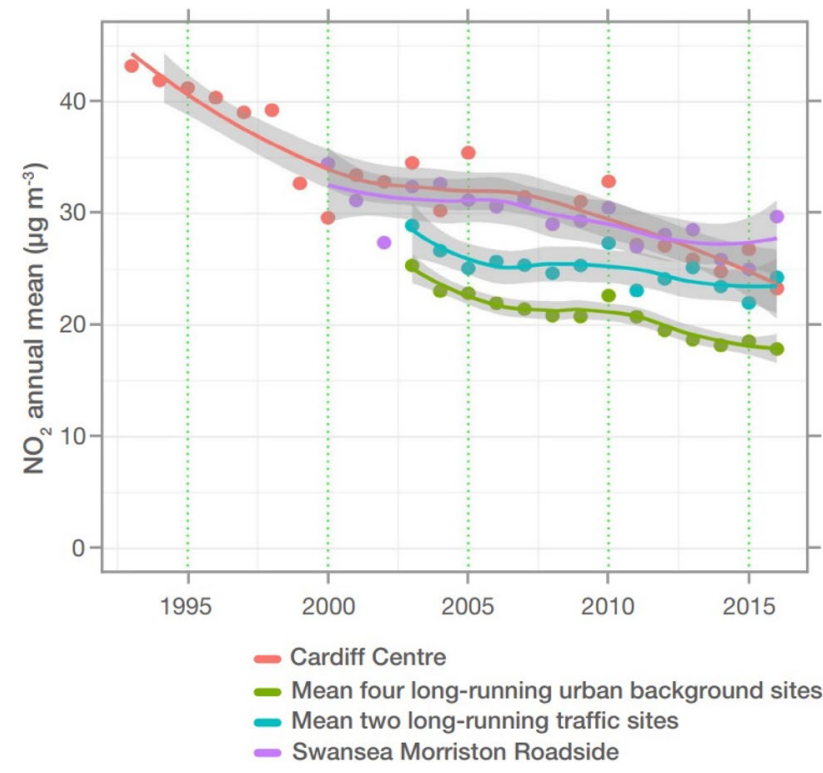

Fig. 2 Annual mean nitrogen dioxide $\left(\mathrm{NO}_{2}\right)$ concentration at long running sites in Wales (Adopted from Welsh Air Quality Forum (2017))

\section{Getmapping aerial imagery}

Getmapping produces high resolution vertical aerial imagery (Getmapping 2018). This study made use of $25 \mathrm{~cm}$ resolution imagery for a $9 \mathrm{~km}^{2}$ area.

\section{Methodology}

Estimates of total road vehicle emissions were calculated for each major road in the city centre, then joined to OS Open Roads data and mapped. Suitable locations for proposed hedges were identified after estimating pavement widths from OS MasterMap data and inspecting GetMapping aerial imagery. Figure 3 shows the overall methodology and is explained in "Mapping average annual daily flow data using OS open roads" and "Identifying suitable locations for proposed hedges" sections.

\section{Mapping average annual daily flow data using OS open roads}

The AADF dataset describes a particular stretch of road using its DfT road number, the junction at the start of that stretch of road, and the junction and the end of the stretch of road. Each stretch of road is also assigned a unique value for the attribute "CP". QGIS was used to identify road links in the OS Open Roads dataset that match the description in the AADF dataset, and then assign the appropriate "CP" value to those road links in OS Open Roads. This allowed the datasets to be joined, and the AADF data to be mapped.

\section{Estimating total emissions}

For each stretch of road, the AADF dataset provides a breakdown of number of vehicles by vehicle type. For this study, the figures for different types of rigid Heavy Goods
Fig. 3 Methodology of roadside emission mapping and site suitability for hedges
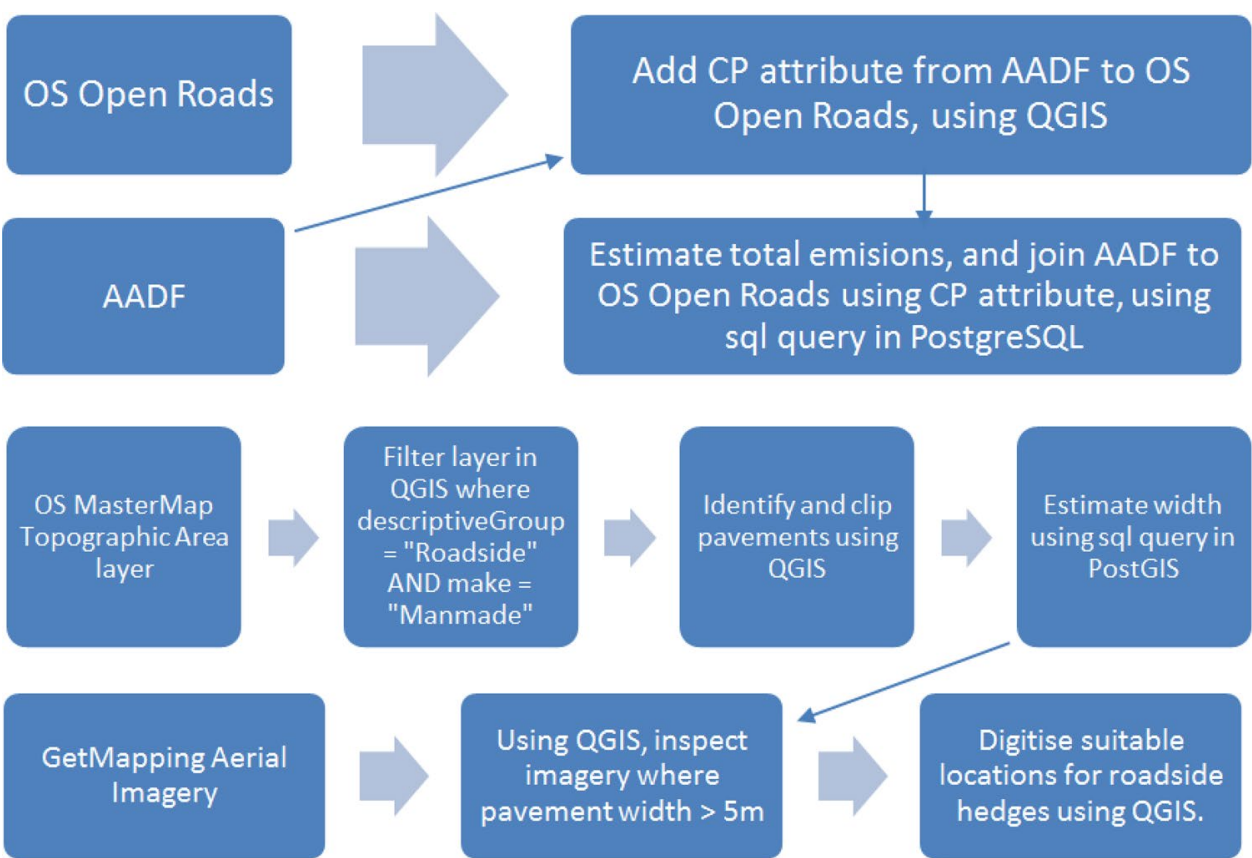

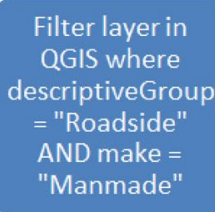

Filter layer in

QGIS where

AND make =

"Manmade"

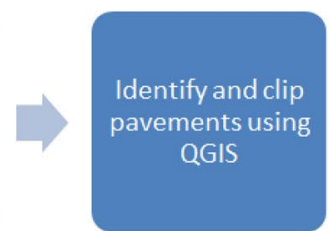

Using QGIS, inspect imagery where pavement width $>5 \mathrm{~m}$

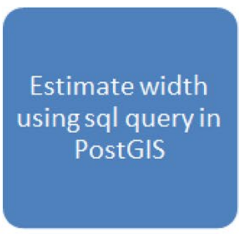

Digitise suitable

locations for roadside

hedges using QGIS. 
Vehicles (HGVs) were combined together, as were those for articulated HGVs. This resulted in six categories: motorcycles, cars and taxis, buses and coaches, light goods vehicles (LGVs), rigid HGVs, and articulated HGVs.

DfT vehicle licensing statistics were then used to proportionally split the cars and taxis, and LGV categories according to fuel type (either petrol or diesel). This resulted in eight categories of vehicle, matching those used in the NAEI road transport emissions factors: motorcycles, petrol cars, diesel cars, buses and coaches, petrol LGVs, diesel LGVs, rigid HGVs, and articulated HGVs.

For each of the eight vehicle types, the number of vehicles on each stretch of road was multiplied by the sum of the urban hot exhaust emission factors for $\mathrm{NO}_{\mathrm{x}}, \mathrm{PM}_{2.5}, \mathrm{PM}_{10}$, and $\mathrm{CO}$. This gave an estimate of the total emissions for each vehicle type on each stretch of road. By summing the estimates for each vehicle type, the total emissions from all vehicles were calculated for each stretch of road. The total emissions data was then joined to the OS Open Roads dataset to create a map of road vehicle emissions.

\section{Estimating pavement widths}

Pavements are represented within OS MasterMap topography layer as topographic area features where the "descriptiveGroup" attribute is set to "Roadside" and the make attribute is set to "Manmade". QGIS was used to identify (and where necessary, clip) pavements located alongside those roads for which emissions data are available. As the pavements were represented as polygons, the width of each section of pavement was estimated as:

width $=2 \times$ area $\div$ perimeter

A map was created of pavement widths, with three classes: $0-2 \mathrm{~m}, 2-5 \mathrm{~m}$, and $>5 \mathrm{~m}$.

\section{Identifying suitable locations for proposed hedges}

Pavements categorised as 2-5 m and 5-11 m wide were considered for the analysis, where those 5-11 m wide are considered most suitable for planting hedges. In most cases the pavement wider than $5 \mathrm{~m}$ would be wide enough to accommodate a $1 \mathrm{~m}$ wide hedge, without too much impact on pedestrian traffic. However, pavement width is not the only constraint that can affect suitability for planting roadside hedges. For example, hedges cannot be planted where access from the pavement to the carriageway is required, such as at bus stops, pedestrian crossings, or parking bays. There were also some sections of pavement where hedges had already been planted.

Aerial imagery of sections of pavement wider than $5 \mathrm{~m}$ was examined to identify where hedges already existed, and where there were other constraints that would prevent the planting of hedges. Once these were taken into account, suitable locations for planting hedges were identified as discussed in results below.

\section{Results}

\section{Total road vehicle emissions}

Road vehicle emissions vary in the city centre as shown in Fig. 4. Central Link, to the south east of the city centre, has total emissions of $46.5 \mathrm{~kg} / \mathrm{km}$. Newport Road in the east, and Heol Y Castell (Castle Street) just north-west of the city centre, have total emissions at 35.8 and $39.6 \mathrm{~kg} / \mathrm{km}$, respectively. The road with the lowest total emissions is Rhodfa Lloyd George (Lloyd George Avenue), to the south of the city centre, where total emissions reach $4.5 \mathrm{~kg} / \mathrm{km}$.

\section{Pavement widths}

Pavement widths also varied a lot as shown in Fig. 5, with some as narrow as $0.4 \mathrm{~m}$, whilst other sections of pavement were up to $10.5 \mathrm{~m}$ wide. A map was created of pavement widths, with three classes: $0-2 \mathrm{~m}, 2-5 \mathrm{~m}$, and $>5 \mathrm{~m}$. This study identified 23 sections of pavement with a width greater than $5 \mathrm{~m}$. These are shown in green, whereas the pavements between 2 and $5 \mathrm{~m}$ wide are shown in yellow in Fig. 5 .

\section{Suitable locations for proposed hedges}

After inspecting aerial imagery of the sections of pavement categorised as 2-5 $\mathrm{m}$ and 5-11 $\mathrm{m}$ wide, considerable number of suitable locations were identified for proposed hedges. This visual inspection helped removing areas where hedges already existed or where not suitable for example where access to bus stop or carriage way is required or at pedestrian crossings, etc. Figure 6 shows the proposed location for roadside hedges, where highly suitable, 5-11 m wide sections are shown in green and moderately suitable, i.e., 2-5 $\mathrm{m}$ wide sections are shown in yellow.

\section{Discussion}

Methodology presented in this paper to map spatial variation of traffic emissions and locating space to grow urban hedges along these roads has been applied in the city centre area of Cardiff city. Pavements wider than $5 \mathrm{~m}$ are considered highly suitable for growing urban hedges. Twelve locations were identified where the pavement is wider than $5 \mathrm{~m}$ and these places are highly suitable for planting roadside hedges. Four locations were identified along Bute Terrace and Adam Street, where the total road vehicle emissions are $24.7 \mathrm{~kg} /$ 


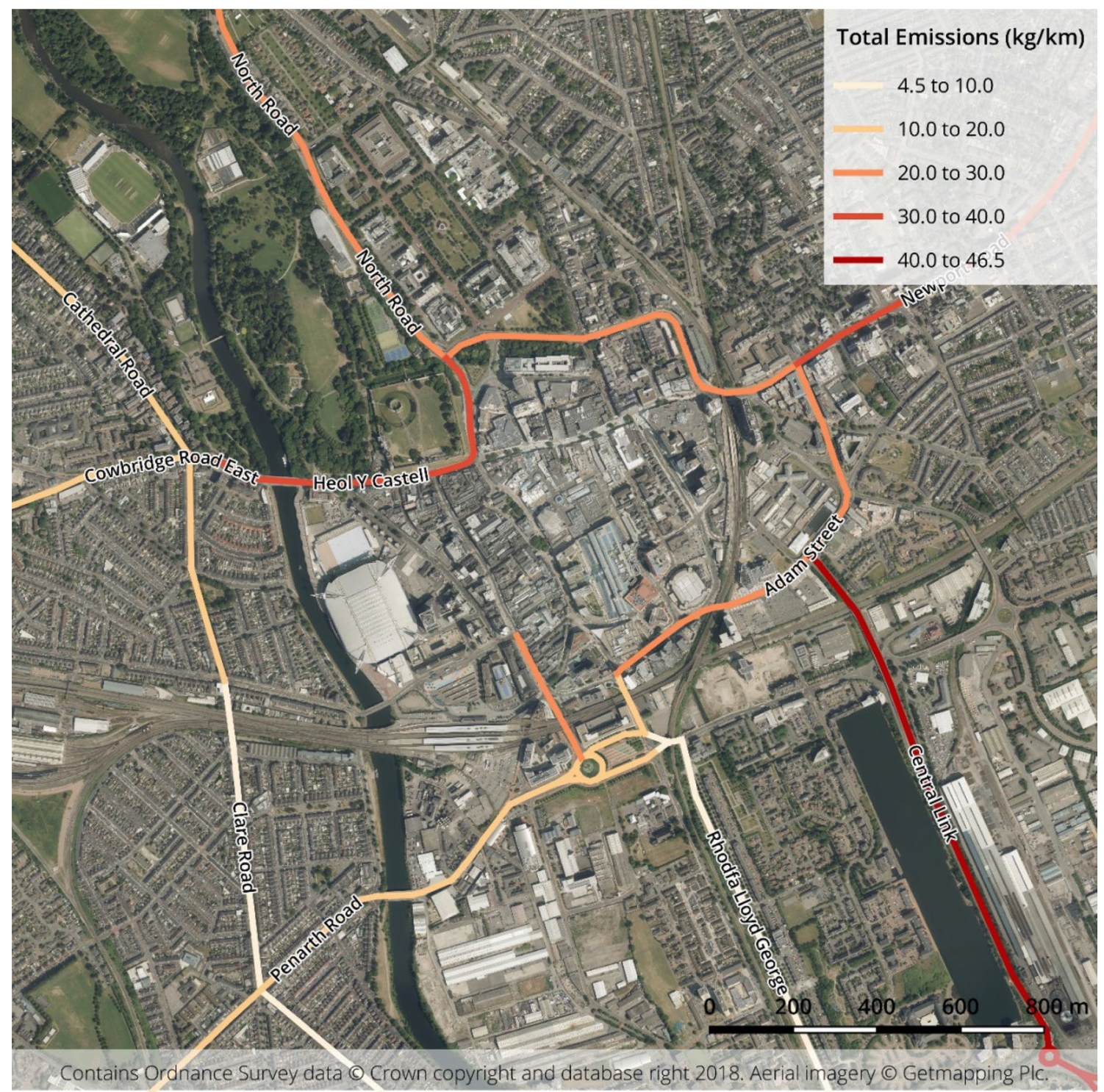

Fig. 4 Estimated total road vehicle emission $(\mathrm{kg} / \mathrm{km})$

$\mathrm{km}$. Two locations were identified along Plas Dumfries and Newport Road (west of Fitzalan Place), where the total road vehicle emissions are $29.7 \mathrm{~kg} / \mathrm{km}$. The location identified on Newport Road also has relatively high volumes of pedestrian traffic, so may be a particularly beneficial location in terms of reducing the impact of road vehicle emissions on pedestrians.

Pavements between 2 and $5 \mathrm{~m}$ are proposed as moderately suitable for growing urban hedges. Several moderately suitable locations where identified for the purpose. However, none of these locations were alongside the roads having high vehicle emissions, e.g., Central Link and Heol Y. Castell. The central link does not have a pavement for pedestrians; therefore it could not be included in the analysis. Nevertheless, there is an unpaved area on both sides of Central Link with some vegetation. This area can be utilised for roadside hedge.

The method of analysing together the high emission road segments and the available space to grow urban hedges provide an effective framework for the decision/ policy makers to take realistic and evidence based decisions to increase urban green space. Along with other types of urban vegetation, such as parks, gardens and urban trees, these proposed urban hedges along busy traffic routs can be helpful to reduce air pollution by providing an air filter at the exhaust pipe level. This will help provide cleaner air to pedestrians and residents and will improve the aesthetics of the urban fabric. It will also help reduce urban heat island effects in summer months. 


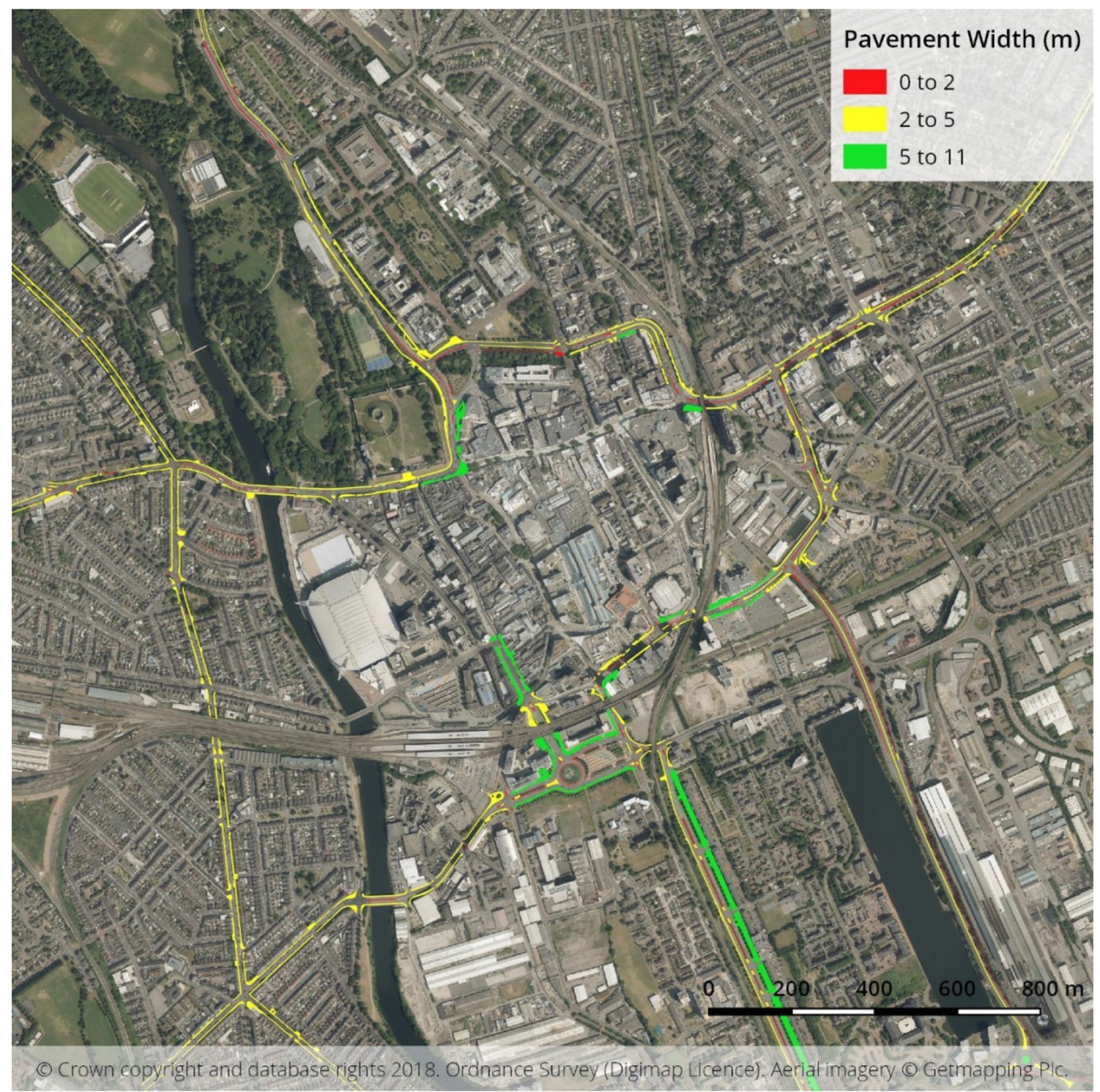

Fig. 5 Estimated width (m) of pavements

\section{Conclusions}

The study is the first of its kind with respect to proposing a methodology to identify space to grow urban hedges along major roads in urban centres. The proposed methodology has been successfully applied in the study area and several segments of pavements have been identified which are highly or moderately suitable to grow hedges. Urban hedges planted along these segments can be helpful in mitigating the impact of road vehicle emissions on pedestrians and to improve the overall air quality of the busy town centres. Study has also provided a methodology to map spatial variation of road vehicle emissions along different segments of roads in city centre area. The methodology has been applied in the study area which provides a good indication of which roads are the largest source of traffic pollutants.

The two outcomes, i.e., the spatial variation in traffic pollution and the most suitable places to grown urban hedges can complement each other and help the policy/ decision makers for making informed decisions for the betterment of urban air quality. It is worth noting that there is a variety of transport and building projects either planned or under construction in and around the city centre. This will result in changes to the layout of many roads and pavements (Cardiff Council 2018). It is, therefore, recommend that the decision makers make use of the methodology and incorporate it into the design of pavements to spare more space for growing urban hedges in the city centre area of Cardiff. 


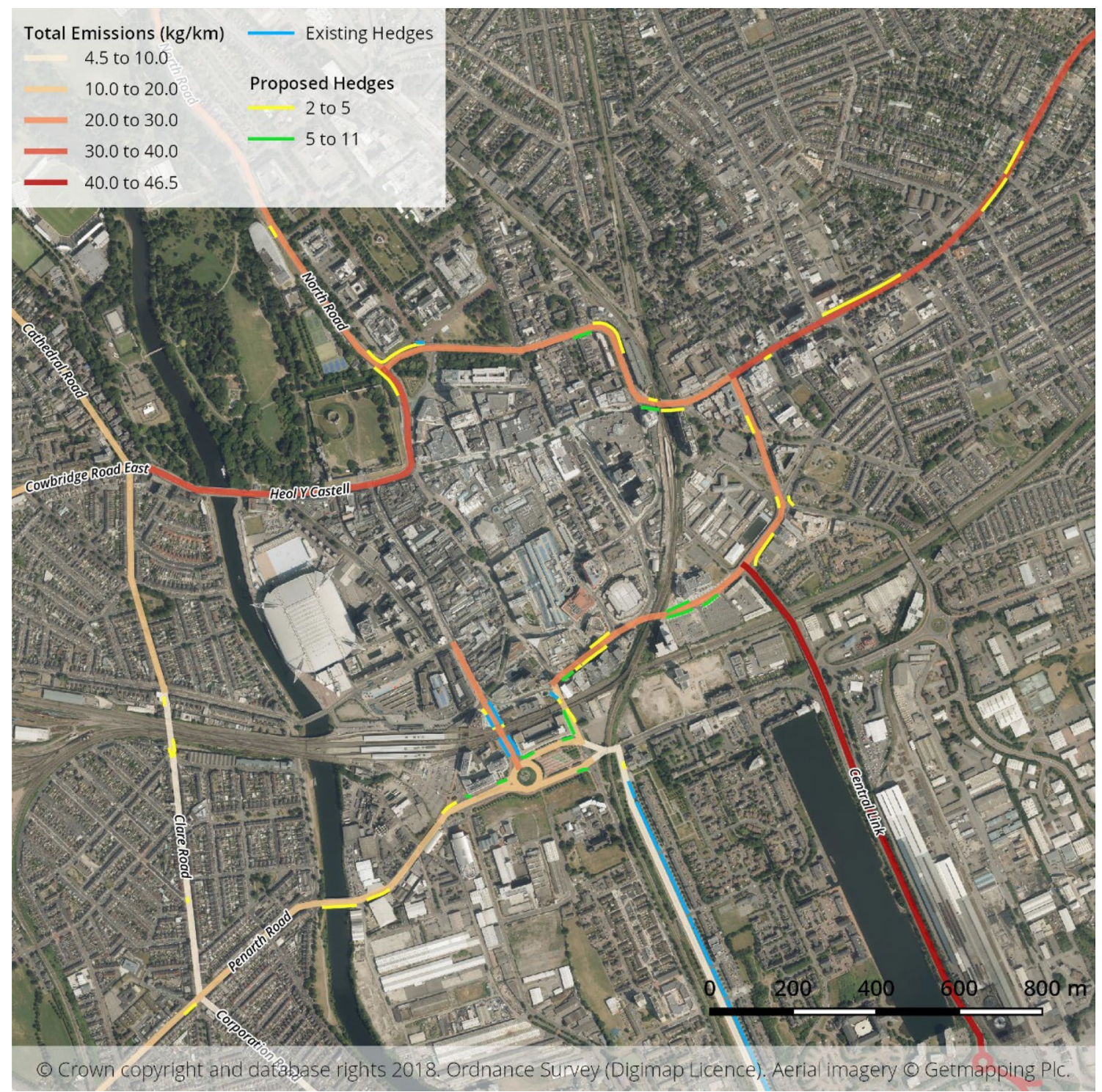

Fig. 6 Suitable locations for planting roadside hedges

The methodology presented in this study is not specific to the study area and can be equally applied in any urban centre. However, the methodology involves some visual inspection of segments for the identification of barriers, e.g., access required for bus stops. It is suggested that methodology can be improved in a future work by incorporation of an automated or semi-automated geoprocessing routine for this purpose. This will significantly improve the time required to implement the methodology and large urban centres like London can be covered with ease.

Open Access This article is distributed under the terms of the Creative Commons Attribution 4.0 International License (http://creat ivecommons.org/licenses/by/4.0/), which permits unrestricted use, 
distribution, and reproduction in any medium, provided you give appropriate credit to the original author(s) and the source, provide a link to the Creative Commons license, and indicate if changes were made.

\section{References}

Abhijith KV et al (2017) Air pollution abatement performances of green infrastructure in open road and built-up street canyon environments-a review. Atmos Environ 162:71-86. https://doi. org/10.1016/j.atmosenv.2017.05.014

Cardiff Council (2018) Cardiff's transport \& clean air green paper: changing how we move around a growing city. https://www. cardiff.gov.uk/ENG/resident/Parking-roads-and-travel/trans port-and-clean-air-green-paper/Documents/Cardiff $\% 27 \mathrm{~s} \% 20$ Transport\%20and\%20Clean\%20Air\%20Green\%20Paper.pdf. Accessed 13 Aug 2018

Department for Transport (2018a) Traffic counts. http://www.dft.gov. uk/traffic-counts/about.php. Accessed 13 Aug 2018

Department for Transport (2018b) Vehicles statistics. https://www. gov.uk/government/collections/vehicles-statistics\#data-tables. Accessed 13 Aug 2018

Escobedo FJ, Nowak DJ (2009) Spatial heterogeneity and air pollution removal by an urban forest. Landsc Urban Plan 90:102-110. https ://doi.org/10.1016/j.landurbplan.2008.10.021

Fantozzi F, Monaci F, Blanusa T, Bargagli R (2015) Spatio-temporal variations of ozone and nitrogen dioxide concentrations under urban trees and in a nearby open area. Urban Clim 12:119-127. https://doi.org/10.1016/j.uclim.2015.02.001

Getmapping (2018) aerial data-GB imagery. http://www.getmapping .com/products/aerial-data-high-resolution-imagery/aerial-data-gbimagery. Accessed 13 Aug 2018

Gosling L, Sparks T, Araya Y, Harvey M, Ansine J (2016) Differences between urban and rural hedges in England revealed by a citizen science project. BMC Ecol. https://doi.org/10.1186/s1289 8-016-0064-1
Gromke C, Jamarkattel N, Ruck B (2016) Influence of roadside hedgerows on air quality in urban street canyons. Atmos Environ 139:75-86. https://doi.org/10.1016/j.atmosenv.2016.05.014

Janhäll S (2015) Review on urban vegetation and particle air pollution-deposition and dispersion. Atmos Environ 105:130-137. https://doi.org/10.1016/j.atmosenv.2015.01.052

Li X-B, Lu Q-C, Lu S-J, He H-D, Peng Z-R, Gao Y, Wang Z-Y (2016) The impacts of roadside vegetation barriers on the dispersion of gaseous traffic pollution in urban street canyons. Urban For Urban Greening 17:80-91. https://doi.org/10.1016/j.ufug.2016.03.006

National Atmospheric Emissions Inventory (2018) Emission factors for transport. http://naei.beis.gov.uk/data/ef-transport. Accessed 13 Aug 2018

Nowak DJ (2006) Institutionalizing urban forestry as a "biotechnology" to improve environmental quality. Urban For Urban Green 5:93-100. https://doi.org/10.1016/j.ufug.2006.04.002

Ordnance Survey (2018a) OS MasterMap topography layer. https:// www.ordnancesurvey.co.uk/business-and-government/products/ topography-layer.html. Accessed 13 Aug 2018

Ordnance Survey (2018b) OS Open Roads. https://www.ordnancesu rvey.co.uk/business-and-government/products/os-open-roads .html. Accessed 13 Aug 2018

Welsh Air Quality Forum (2016) Air pollution in Wales 2015. https:// airquality.gov.wales/sites/default/files/documents/2016-12/50716 1019_AQ_wales_2015_v12_Press.pdf. Accessed 13 Aug 2018

Welsh Air Quality Forum (2017) Air pollution in Wales 2016. https ://airquality.gov.wales/sites/default/files/documents/2017-11/ AQ_wales_2016_v5.pdf. Accessed 13 Aug 2018

Wolch JR, Byrne J, Newell JP (2014) Urban green space, public health, and environmental justice: the challenge of making cities 'just green enough'. Landsc Urban Plan 125:234-244. https://doi. org/10.1016/j.landurbplan.2014.01.017

Yin S, Shen Z, Zhou P, Zou X, Che S, Wang W (2011) Quantifying air pollution attenuation within urban parks: an experimental approach in Shanghai, China. Environ Pollut 159:2155-2163. https://doi.org/10.1016/j.envpol.2011.03.009 